Michael M. Peng $\cdot$ Mark L. Wilson

Robert E. Holland · Steven R. Meshnick

Altaf A. Lal · Lihua Xiao

\title{
Genetic diversity of Cryptosporidium spp. in cattle in Michigan: implications for understanding the transmission dynamics
}

Received: 18 October 2002 / Accepted: 14 January 2003/Published online: 26 February 2003

(C) Springer-Verlag 2003

\begin{abstract}
Epidemiological and molecular data on 248 bovine, 17 human, and 16 water samples of Cryptosporidium spp. collected from the lower peninsula of Michigan between 1997 and 2000 were analysed. Cryptosporidium parvum bovine genotype and Cryptosporidium andersoni were found in 56 and four cattle samples, respectively. A total of six C. parvum subgenotypes were found in 34 bovine samples, and five of the eight farms had two or three subgenotypes in cattle. Six water samples from these farms had $C$. andersoni, five had the C. parvum bovine genotype, and one had Cryptosporidium muris. In contrast, four PCR-positive human samples produced the $C$. parvum bovine genotype and two had the $C$. parvum human genotype. Among the $C$. parvum bovine genotype samples, two human samples and one water sample had subgenotypes identical to those found on cattle farms. The results of this study demonstrate the potential use of molecular methods in tracking the transmission of Cryptosporidium.
\end{abstract}

\section{Introduction}

Cryptosporidium parasites infect humans and domestic animals such as cattle, pigs, goats, cats and dogs (Fayer

M.M. Peng $\cdot$ A.A. Lal $\cdot$ L. Xiao $(\bowtie)$

Division of Parasitic Diseases,

Center for Disease Control

and Prevention, Atlanta,

GA 30341, USA

E-mail: 1xiao@cdc.gov

Tel.: + 1-770-4884840

Fax: + 1-770-4884454

M.M. Peng · M.L. Wilson · S.R. Meshnick

Department of Epidemiology, School of Public Health, University of Michigan, Ann Arbor, MI 48109-2029, USA

R.E. Holland

College of Veterinary Medicine,

Iowa State University, Ames, IA 50011, USA et al. 2000). Two Cryptosporidium spp., Cryptosporidium parvum and Cryptosporidium andersoni, are found in cattle, with the former also infecting humans and other mammals. Significant biological differences exist between the two Cryptosporidium parasites in cattle. $C$. parvum mostly infects the intestine of neonatal calves, has high infection rates and intensities, and has an oocyst shedding duration of only 1-2 weeks. In contrast, C. andersoni infects the abomasum of juvenile and adult cattle, has low infection rates and intensities, and has a long oocyst shedding duration of months to years (Anderson 1991a, 1991b; Lindsay et al. 2000). Several Cryptosporidium genotypes have been recognized in what is traditionally considered as C. parvum, notably a human strain (human genotype or genotype 1) that largely infects humans and a bovine strain (bovine genotype or genotype 2) that infects both humans and some farm animals such as cattle, sheep and goats (Morgan et al. 2000; Xiao et al. 2000).

Because of the ubiquitous occurrence of Cryptosporidium oocysts in animals and the environment, it is possible that parasites of zoonotic origin play an important role in human cryptosporidiosis. Transmission from animals to humans can occur either through direct contact or indirectly through a vehicle such as water. Several well-documented examples involve petting zoos and foodborne outbreaks (Current et al. 1983; Miron et al. 1991; Millard et al. 1994; Peng et al. 1997). However, waterborne transmission still appears to be one of the most important factors in the epidemiology of human cryptosporidiosis (Rose 1997).

Various molecular tools for species differentiation, genotyping and subgenotyping have been developed recently to characterize the transmission of Cryptosporidium (Fayer et al. 2000; Morgan et al. 2000). These molecular techniques have led to the discovery of several Cryptosporidium spp. in humans, and to a better understanding of the transmission to humans (Morgan et al. 2000; Xiao et al. 2000). The use of such tools in the characterization of bovine infection, however, has been scarce. One study in the Netherlands identified two 
subgenotypes of the $C$. parvum bovine genotype in cattle on one farm (Huetink et al. 2001). In this study, 248 bovine, 17 human, and 16 water samples collected from the lower peninsula of the state Michigan between 1997 and 2000 were analysed using a small subunit (SSU) rRNA gene-based PCR-RFLP tool for species and genotype differentiation (Xiao et al. 2001a), and a 60-kDa glycoprotein (GP60, also known as pg15/45/60, Cpgp40/ 15 , and gp17) gene-based sequencing tool for subgenotyping (Strong et al. 2000).

\section{Materials and methods}

\section{Samples and sample preparation}

A total of 17 human and 248 cattle fecal samples as well as 16 dairy farm water samples collected from the lower peninsula of the state Michigan were used in this study. The human samples were obtained from hospitals, clinics and the Michigan State Health Department from 1998 to 2000 from patients diagnosed with cryptosporidiosis. Bovine samples were collected from calves and cows with diarrhea on 12 farms in nine counties from 1997 to 1999. The farms were chosen because they had previously been cooperative in such research. Human samples were stored in formalin, whereas bovine samples were stored in a $-20^{\circ} \mathrm{C}$ freezer prior to analysis. Water samples were collected from seven farms (13 sites) during the summer of 2000, using Method 1622 recommended by the U.S. Environmental Protection Agency. Water sample locations included fecal slurry, pools or puddles adjacent to pens with cows or calves, and streams that flowed from farms or fields where these animals were kept. The collection protocol involved pumping $\sim 101$ of water through an Envirocheck filter (Pall Gelman Laboratory, Ann Arbor, Mich.), elution of the filter retentions, and concentration of the sample by centrifugation. Cryptosporidium oocysts in water samples were isolated by immunomagnetic separation (IMS), using immunomagnetic beads coated with monoclonal antibodies against Cryptosporidium (Dynal, Oslo, Norway), and following the manufacturer-recommended procedures included in the kit. Purified Cryptosporidium oocysts, without the detachment of immunomagnetic beads, were stored at $-20^{\circ} \mathrm{C}$ before used in DNA extraction (Xiao et al. 2001b).

\section{Isolation of genomic DNA}

DNA was extracted from stool samples or IMS-purified Cryptosporidium oocysts by alkaline digestion and phenol-chloroform extraction, followed by DNA purification using a commercial kit. Briefly, $66.6 \mu \mathrm{l}$ of $1 \mathrm{M} \mathrm{KOH}$ and $18.6 \mu \mathrm{l}$ of $1 \mathrm{M}$ DTT (dithiothreitol) were added to a $1.5 \mathrm{ml}$ microcentrifuge tube containing $100-200 \mu \mathrm{l}$ of stool or the IMS concentrate from water samples. After incubation at $65^{\circ} \mathrm{C}$ for $15 \mathrm{~min}$, the solution was neutralized with $8.6 \mu \mathrm{l}$ of $25 \% \mathrm{HCl}$ and buffered with $160 \mu \mathrm{l}$ of $2 \mathrm{M}$ Tris- $\mathrm{HCl}$ (pH 8.3). The DNA was extracted with $250 \mu \mathrm{l}$ phenol:chloroform:isoamyl alcohol (Invitrogen, Carlsbad, Calif.) after thorough mixing and centrifugation at $6,000 \mathrm{rpm}$ for $5 \mathrm{~min}$. The supernatant was transferred to a $2.0 \mathrm{ml}$ Eppendorf tube containing $1.0 \mathrm{ml}$ of ASL buffer from the QIAamp DNA Stool Mini Kit (Qiagen, Valencia, Calif.). The DNA was further purified following the manufacturer-suggested procedures. DNA was stored at $-70^{\circ} \mathrm{C}$ before it was used in molecular analysis.

Cryptosporidium species differentiation and genotyping

Cryptosporidium spp. and genotypes present were diagnosed by a PCR-RFLP technique (Xiao et al. 2001a). In this method, a segment (about $833 \mathrm{bp}$ ) of the Cryptosporidium SSU rRNA gene was amplified by nested PCR. Species and genotype diagnosis was made by restriction digestion of the secondary PCR product with $S s p$ I (New England BioLabs, Beverly, Mass.) and Vsp I. (Promega, Madison, Wis.). Water samples and bovine samples positive for $C$. andersoni were digested with Dde I (New England BioLabs) to distinguish between Cryptosporidium muris and C. andersoni (Xiao et al. 2001b). Each sample was examined at least twice by independent PCR-RFLP analyses.

\section{Subgenotyping}

Isolates of the C. parvum bovine genotype were subgenotyped by sequence analysis of the GP60 gene (Strong et al. 2000; Peng et al. 2001). The primers used to amplify GP60 were 5'-ATAGTCTCCGCTGTATTC-3' and 5'-GCAGAGGAACCAGCATC$3^{\prime}$ (primary PCR) and $5^{\prime}$-TCCGCTGTATTCTCAGCC-3' and 5'-GAGATATATCTTGGTGCG-3' (secondary PCR), producing fragments of about 950 and $550 \mathrm{bp}$, respectively. These primers were designed based on sequences conserved among all known $C$. parvum GP60 alleles. Each PCR sample contained $1 \times$ Perkin-Elmer (Norwalk, Conn.) PCR buffer, $3 \mathrm{mM} \mathrm{MgCl} 2,200 \mu \mathrm{M}$ of each deoxynucleoside triphosphate, $200 \mathrm{nM}$ of the forward and reverse primers, 5 units of Taq polymerase, and $0.5-2 \mu \mathrm{l}$ of DNA template (for primary PCR) or $2 \mu \mathrm{l}$ of primary PCR product (for secondary PCR) in a $100 \mu \mathrm{l}$ reaction. The PCR program was comprised of 35 cycles of denaturation at $94^{\circ} \mathrm{C}$ for $45 \mathrm{~s}$, annealing at $50^{\circ} \mathrm{C}$ for $45 \mathrm{~s}$, and extension at $72^{\circ} \mathrm{C}$ for $60 \mathrm{~s}$, with an initial denaturation at $95^{\circ} \mathrm{C}$ for $3 \mathrm{~min}$ and a final extension at $72^{\circ} \mathrm{C}$ for $10 \mathrm{~min}$. Each sample was analyzed twice by GP60 PCR. All PCR products were purified with the Wizard PCR Prep Kit (Promega) and sequenced in both directions on an ABI3100 automated sequencer (Applied Biosystems, Foster City, Calif.) using forward and reverse primers. The GP60 nucleotide sequences obtained from this study were aligned against each other and those from previous studies (Strong et al. 2000; Peng et al. 2001; Sulaiman et al. 2001; Leav et al. 2002) using GCG software (Genetics Computing Group, Madison, Wis.). A neighbor-joining tree was constructed from the aligned sequences as previously described, using genetic distances calculated based on the Kimura 2-parameter model and the program Treecon (Xiao et al. 1999). The nucleotide sequences reported in this paper are available in the GenBank, EMBL and DDBJ databases under the accession numbers AY149610-AY149617.

\section{Results}

Cryptosporidium species differentiation and genotyping

Among the 248 cattle samples tested, 60 (24.2\%) produced positive PCR signals (Table 1). RFLP analysis indicated that 56 of the PCR-positive samples had the $C$. parvum bovine genotype (93\%), whereas four samples were identified as $C$. andersoni $(7 \%)$. C. andersoni was found in only two of the 12 sites (farms 1 and 10), both of which were in the same county. The infection rates of the $C$. parvum bovine genotype on each farm varied from 0 to $100 \%$. However, the farms with no Cryptosporidium or high infection rates were those with only limited sampling. Thus, the infection rates of the $C$. parvum bovine genotype on farms with reasonable numbers of samples $(>20)$ were between $13.6 \%$ and $20.0 \%$ (Table 1$)$.

Six $(35.3 \%)$ of the 17 formalin-preserved, microscopically positive stool samples from humans were positive by PCR; four (66.7\%) of these were genotyped 
Table 1 Cryptosporidium species and subgenotype distribution in cattle on 12 farms in southern Michigan. All C. parvum isolates belonged to the bovine genotype

\begin{tabular}{lllllll}
\hline Farm & $\begin{array}{l}\text { No. } \\
\text { samples }\end{array}$ & $\begin{array}{l}\text { No. } \\
\text { positive }\end{array}$ & $\begin{array}{l}\text { Cryptosporidium } \\
\text { parvum }\end{array}$ & $\begin{array}{l}\text { Cryptosporidium } \\
\text { andersoni }\end{array}$ & $\begin{array}{l}\text { No. } \\
\text { subgenotyped }\end{array}$ & $\begin{array}{l}\text { C. parvum } \\
\text { subgenotype }\end{array}$ \\
\hline 1 & 94 & 13 & 10 & 3 & 6 & $\mathrm{II}_{\mathrm{a} 1}(3), \mathrm{II}_{\mathrm{a} 2}(1), \mathrm{II}_{\mathrm{a} 4}(2)$ \\
2 & 60 & 12 & 12 & 0 & 7 & $\mathrm{II}_{\mathrm{a} 1}(5), \mathrm{II}_{\mathrm{a} 2}(2)$ \\
3 & 22 & 3 & 3 & 0 & 2 & $\mathrm{II}_{\mathrm{a} 4}(2)$ \\
4 & 21 & 3 & 3 & 0 & 0 & - \\
5 & 12 & 5 & 5 & 0 & 3 & $\mathrm{II}_{\mathrm{a} 4}(2), \mathrm{II}_{\mathrm{a} 7}(1)$ \\
6 & 12 & 10 & 10 & 0 & 7 & $\mathrm{II}_{\mathrm{a} 3}(7)$ \\
7 & 2 & 0 & 0 & 0 & 0 & - \\
8 & 5 & 4 & 4 & 0 & 4 & $\mathrm{II}_{\mathrm{a} 3}(1), \mathrm{II}_{\mathrm{a} 4}(1), \mathrm{II}_{\mathrm{a} 6}(2)$ \\
9 & 2 & 1 & 1 & 0 & 0 & - \\
10 & 4 & 3 & 2 & 1 & 1 & $\mathrm{II}_{\mathrm{a} 7}(1)$ \\
11 & 1 & 1 & 1 & 0 & 0 & - \\
12 & 13 & 5 & 5 & 0 & 4 & $\mathrm{II}_{\mathrm{a} 4}(3), \mathrm{II}_{\mathrm{a} 6}(1)$ \\
Total & 248 & 60 & 56 & 4 & 34 & 6 \\
\hline
\end{tabular}

as the $C$. parvum bovine type and two $(33.3 \%)$ as the $C$. parvum human type. None of the human samples were from residents of the same county as the animal samples. The long-term storage of stools in formalin had probably reduced the sensitivity of PCR detection of Cryptosporidium infection. Eleven $(68.8 \%)$ of the 16 water samples collected were positive for Cryptosporidium by PCR. RFLP analysis revealed that four were positive for the $C$. parvum bovine, five for $C$. andersoni, one for $C$. muris, and one for both the $C$. andersoni and C. parvum bovine genotypes.

\section{Subgenotype analysis}

All samples that were positive for the $C$. parvum bovine genotype by the SSU rRNA PCR were subgenotyped by sequence analysis of the GP60 gene. GP60 sequences were obtained from 34 bovine samples, three human samples and two water samples. The reduced sensitivity of the subgenotyping method in comparison with the species differentiation and genotyping technique was likely the result of differences in the copy number of diagnostic gene targets: GP60 gene has only a single copy within the genome, whereas the SSU rRNA gene has five copies (Le Bancq et al. 1997; Strong et al. 2000). Even though the GP60 subgenotyping primers were based on DNA sequences conserved among all known C. parvum subgenotype alleles, it is impossible to totally exclude the possibility that some of the samples might have new subgenotype alleles that are different from the known GP60 sequences. This may explain why GP60 sequences were obtained from only 34 of the 56 bovine samples, three of the four human samples and two of the four water samples that were positive by SSU rRNA PCR for the C. parvum bovine genotype. Samples positive for $C$. andersoni or $C$. muris were not analyzed for GP60, because GP60 primers used in this study do not amplify DNA of these two Cryptosporidium parasites (L. Xiao unpublished data).

A total of eight subgenotypes of the C. parvum bovine genotype were seen. There were six subgenotypes in the bovine samples, three in the human samples, and two in the water samples. Two of the three subgenotypes in humans (samples H-S1 and H-A2b) and one of the two subgenotype in water (sample W-M1) were also found in the bovine samples. Seven of the eight subgenotypes belonged to the allele group IIa (Fig. 1), and differed from each other mostly in the number of a trinucleotide repeats (Fig. 2). These are referred to as subgenotypes $\mathrm{II}_{\mathrm{a} 1}-\mathrm{II}_{\mathrm{a} 7}$. One subgenotype in water sample $\mathrm{W}-\mathrm{M} 8$ was quite different from the rest of the samples and from known GP60 subgenotypes (Fig. 2), whereas the other subgenotype $\left(\mathrm{II}_{\mathrm{a} 4}\right)$ in one water sample from farm 1 was identical to one of the three subgenotypes from cattle on the same farm (Fig. 1).

Most (74.4\%) of the GP60-positive samples belonged to three subgenotypes: $\mathrm{II}_{\mathrm{a} 1}(23.1 \%), \mathrm{II}_{\mathrm{a} 3}(20.5 \%)$ and $\mathrm{II}_{\mathrm{a} 4}(30.8 \%)$. The rest of the subgenotypes contained only from one to three samples (Figs. 1, 3, and Table 1). Subgenotype $\mathrm{II}_{\mathrm{a} 4}$ was the most widely distributed C. parvum bovine genotype, having been found in a single human sample, a single water sample, and in cattle from five farms. In contrast, subgenotypes $\mathrm{II}_{\mathrm{a} 1}$, and $\mathrm{II}_{\mathrm{a} 2}$ were only found in southern Michigan, whereas other subgenotypes were found on only one or two cattle farms (Fig. 3). Even though some farms had a predominant $C$. parvum subgenotype (such as $\mathrm{II}_{\mathrm{a} 3}$ on farm 6 and $\mathrm{II}_{\mathrm{a} 1}$ on farm 2), most had two (farms 2,5 , and 12) or three (farms 1 and 8) subgenotypes circulating in cattle. Subgenotype information was not available for four of the 12 farms studied because of the small numbers of samples available (Table 1).

\section{Discussion}

The results of this study reveal the diversity of Cryptosporidium parasites in a small geographic area. The C. parvum bovine genotype or C. andersoni, was found in 60 of 248 cattle from central and southern Michigan. Likewise, $C$. muris or $C$. andersoni and/or the $C$. parvum bovine genotype were found in 11 of the 16 water samples taken near or from cattle farms, and both the C. parvum bovine or human genotypes were found in six humans from the same general area. Such diversity of 
Fig. 1 The distribution of subgenotypes of the genotype in cattle, humans and water in southern Michigan as shown by a neighbor-joining tree of the GP60 sequences. Sample IDs beginning with $B$, $H$ and $W$ denote bovine, human and water samples, respectively. Numbers in parentheses are IDs for cattle farms. With the exception of the subgenotype found in water sample W-M8, seven related subgenotypes are shown sequences among eight subgenotypes of the $C$. parvum human genotype. Dots denote nucleotide identity to sample B-254 (subgenotype $\mathrm{II}_{\mathrm{a} 6}$ ), and dashes denote deletions. $H$-A2C: subgenotype $\mathrm{II}_{\mathrm{a} 5}$; $B$-194: subgenotype $\mathrm{II}_{\mathrm{a} 4} ; B-36$ : subgenotype $\mathrm{II}_{\mathrm{a} 7}$; $B$-244: subgenotype $\mathrm{II}_{\mathrm{a} 1}$; $B$-39: subgenotype $\mathrm{II}_{\mathrm{a} 2} ; B$-255: subgenotype $\mathrm{II}_{\mathrm{a} 3} ; W$-M8: new subgenotype allele in water Cryptosporidium parvum bovine

Fig. 2 Diversity in the GP60

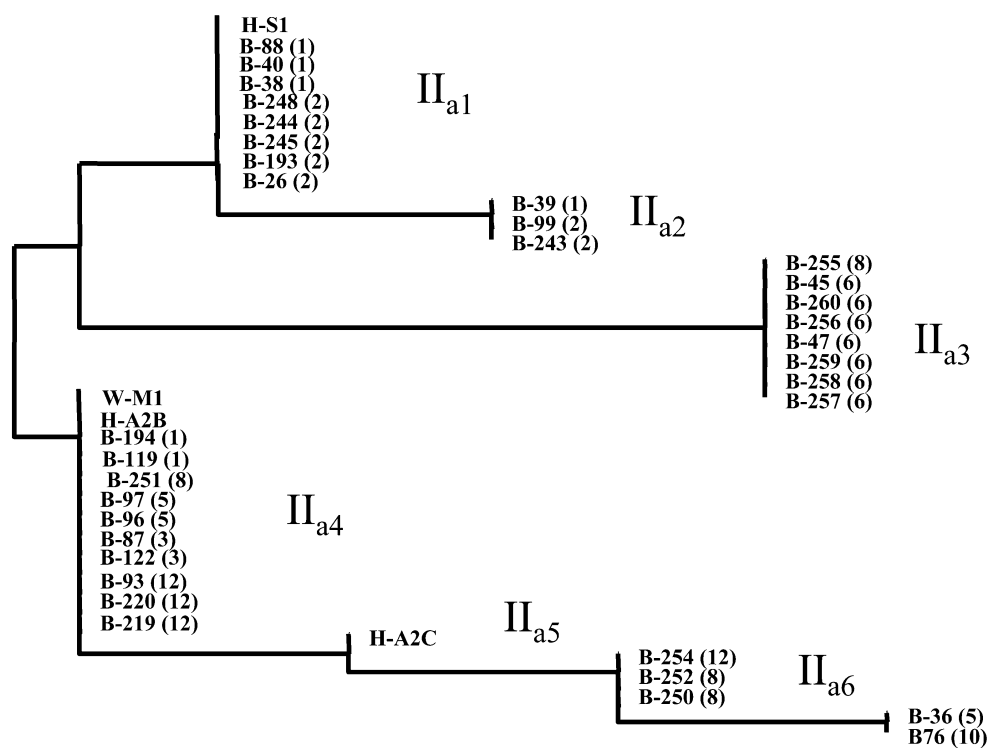

$\mathrm{II}_{\mathrm{a} 7}$

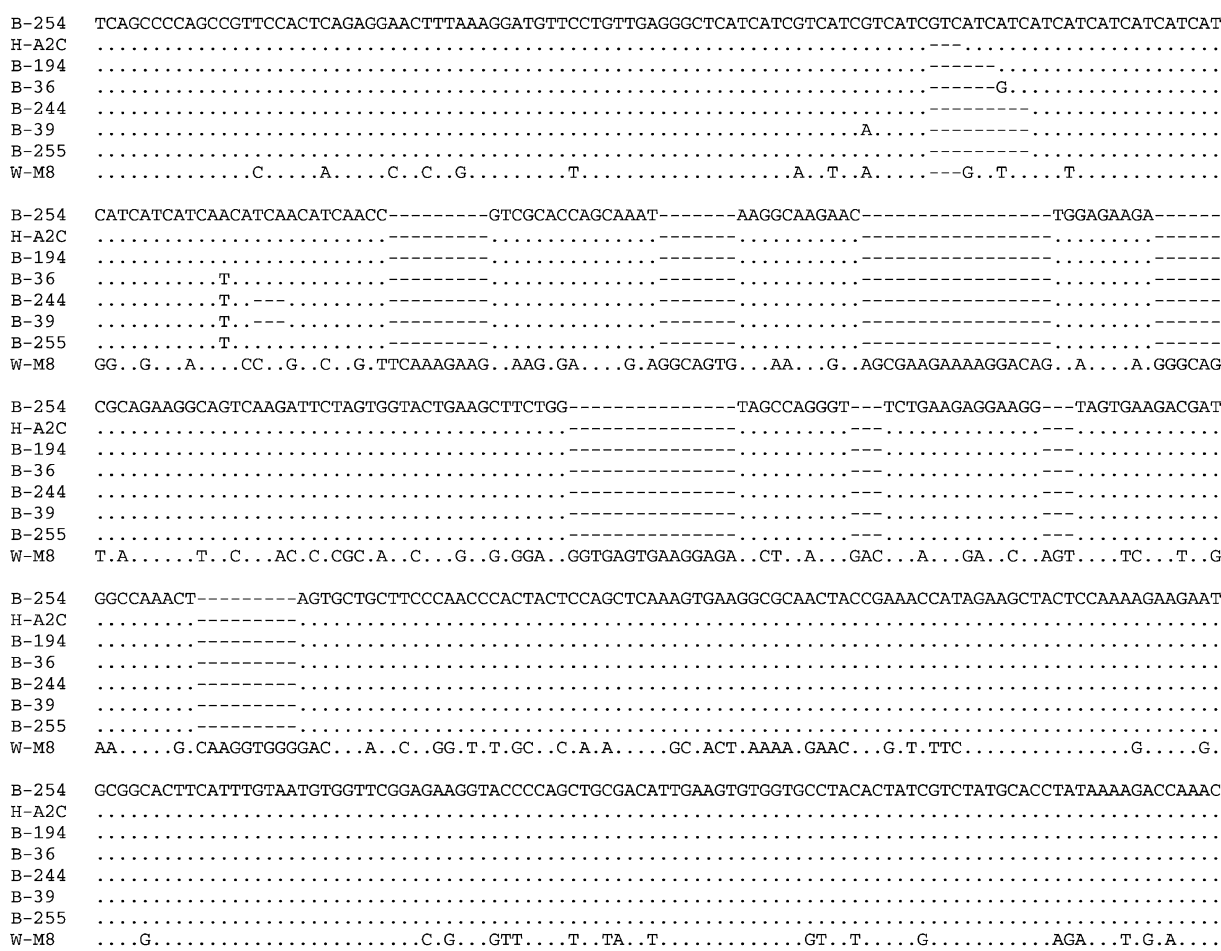

Cryptosporidium parasites in cattle, humans and water samples has been reported before (McLauchlin et al. 2000; Xiao et al. 2001b; Ward et al. 2002). Nevertheless, this study represents the first report in which Cryptosporidium parasites from cattle, humans, and water from the same geographic area have been examined.

The results of subgenotype analysis support the complexity of Cryptosporidium infection. Six subgenotypes of the C. parvum bovine genotype were found in 34 samples from eight cattle farms. Five of the eight farms had from two to three subgenotypes circulating in cattle. The three farms with a single subgenotype of C. parvum could also have multiple subgenotypes in cattle, because only one or two isolates were subgenotyped on two of those farms. Previously, two subgenotypes of the C. parvum bovine genotype had been found in samples collected from a dairy farm in the Netherlands (Huetink et al. 2001). The existence of heterogeneous $C$. parvum bovine genotypes on a farm could be the result of a frequent exchange of calves between farmers and/or the introduction of new animals This is supported by the fact that cattle from two of the farms (2 and 6) in this study had a predominant subgenotype. Two of the subgenotypes of the $C$. parvum bovine genotype had a 
Fig. 3 Geographic distribution of subgenotypes of the C. parvum bovine genotype in cattle in Michigan

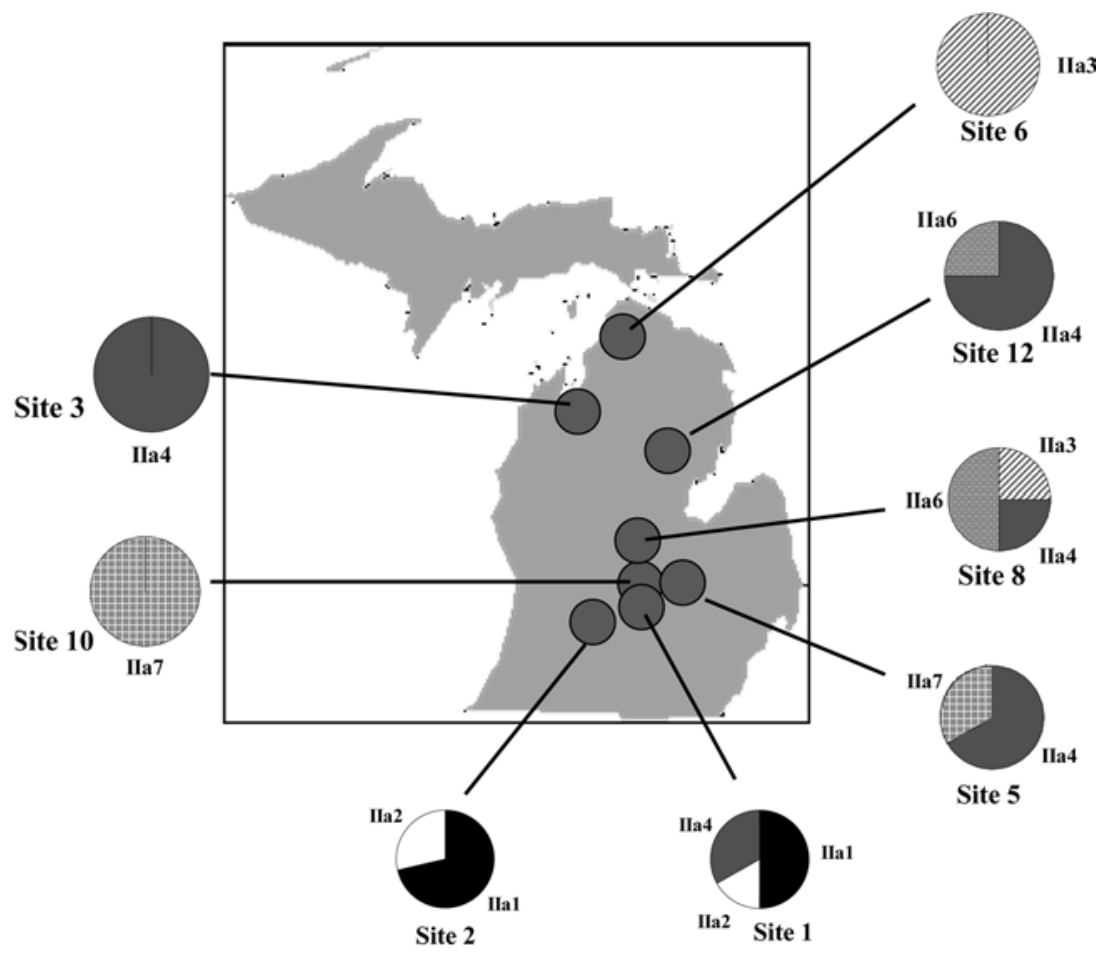

wider distribution than the other subgenotypes: subgenotype $\mathrm{II}_{\mathrm{a} 4}$ is also present in West Virginia and Oklahoma, whereas subgenotype $\mathrm{II}_{\mathrm{a} 1}$ has been seen in cattle in Iowa, Ohio, Minnesota, Alabama, Georgia, Idaho, Kansas and Portugal, as well as in humans from Louisiana and Portugal (Xiao L. unpublished data). It is unclear whether genetic fitness or unusual transport is responsible for the wide geographic distribution of these two subgenotypes.

One interesting observation is the difference in the distribution of Cryptosporidium parasites in cattle and water, even though water samples were collected on or near cattle farms. As expected, most of the Cryptosporidium parasites in cattle belonged to the $C$. parvum bovine genotype, with $C$. andersoni only occasionally seen. In contrast, more $C$. andersoni was seen in water samples than the C. parvum bovine genotype. Frequent detection of $C$. andersoni was also previously reported in mid-western US rivers (Xiao et al. 2001b). Because C. andersoni mostly infects mature cattle, it seems likely that dairy cows were responsible for some of the Cryptosporidium contamination in water. It has been generally assumed that calves and lambs are responsible for most of the contamination of water with Cryptosporidium oocysts, largely because of the high prevalence and intensity of infection in these animals (Sischo et al. 2000; Graczyk et al. 2000). Mature cattle apparently contribute significantly to Cryptosporidium oocyst contamination in water, probably due to the bulk volume of feces excreted and the long shedding period of $C$. andersoni.

The small sample size prevents definitive conclusions about the relationship among Cryptosporidium in cattle, humans and water in this study. Two of the C. parvum bovine genotype isolates from humans were identical to those isolated from cattle in the same region (subgenotypes $\mathrm{II}_{\mathrm{a} 1}$ and $\mathrm{II}_{\mathrm{a} 4}$ ). These two subgenotypes, however, are also the most widely distributed $C$. parvum bovine genotype parasites and have been found in other parts of the country (see above). Therefore, it is difficult to make a direct connection between the human infections and the bovine parasites. Likewise, a single water sample taken from near a farm had the same subgenotype $\left(\mathrm{II}_{\mathrm{a} 4}\right)$ of $C$. parvum as the cattle on the farm. Again, unlike most other subgenotypes seen in this study, this subgenotype has a wide geographic distribution. The lower prevalence of Cryptosporidium in cattle than in water is also expected, because the drinking water for cattle on the study farms came from wells or was treated, which would have lower Cryptosporidium contamination. In addition, both calves and cows were included in this study, and adult cattle are known to have low Cryptosporidium infection rates.

The results of this small scale study demonstrate the potential for using molecular tools to characterize the ecology of cryptosporidiosis in certain environmental settings. Recently, there has been increased interest in the assessment of the contribution of agricultural, environmental, ecologic, and climatologic factors to Cryptosporidium oocyst contamination in watershed and source water (Graczyk et al. 2000; Rouquet et al. 2000; Sischo et al. 2000; Medema and Schijven 2001; Ono et al. 2001; Jellison et al. 2002). The use of high-resolution molecular tools and systematic sampling in combination with conventional methodologies could lead to a better understanding of the ecology of cryptosporidiosis in different environmental settings. 


\section{References}

Anderson BC (1991a) Cryptosporidium muris in cattle. Vet Rec 129:20

Anderson BC (1991b) Prevalence of Cryptosporidium muris-like oocysts among cattle populations of the United States: preliminary report. J Protozool 38:14S-15S

Current WL, Reese NC, Ernst JV, Bailey WS, Heyman MB, Weinstein WM (1983) Human cryptosporidiosis in immunocompetent and immunodeficient persons. Studies of an outbreak and experimental transmission. $\mathrm{N}$ Engl $\mathrm{J}$ Med 308:1252-1257

Fayer R, Morgan U, Upton SJ (2000) Epidemiology of Cryptosporidium: transmission, detection and identification. Int $\mathbf{J}$ Parasitol 30:1305-1322

Graczyk TK, Evans BM, Shiff CJ, Karreman HJ, Patz JA (2000) Environmental and geographical factors contributing to watershed contamination with Cryptosporidium parvum oocysts. Environ Res 82:263-271

Huetink RE, van der Giessen JW, Noordhuizen JP, Ploeger HW (2001) Epidemiology of Cryptosporidium spp. and Giardia duodenalis on a dairy farm. Vet Parasitol 102:53-67

Jellison KL, Hemond HF, Schauer DB (2002) Sources and species of Cryptosporidium oocysts in the Wachusett reservoir watershed. Appl Environ Microbiol 68:569-575

Leav BA, Mackay MR, Anyanwu A, O'Connor RM, Cevallos AM, Kindra G, Rollins NC, Bennish ML, Nelson RG, Ward HD (2002) Analysis of sequence diversity at the highly polymorphic Cpgp40/15 locus among Cryptosporidium isolates from human immunodeficiency virus-infected children in South Africa. Infect Immun 70:3881-3890

Le Blancq SM, Khramtsov NV, Zamani F, Upton SJ, Wu TW (1997) Ribosomal RNA gene organization in Cryptosporidium parvum. Mol Biochem Parasitol 90:463-478

Lindsay DS, Upton SJ, Owens DS, Morgan UM, Mead JR, Blagburn BL (2000) Cryptosporidium andersoni n. sp. (Apicomplexa: Cryptosporiidae) from cattle, Bos taurus. J Eukaryot Microbiol 47:91-95

McLauchlin J, Amar C, Pedraza-Diaz S, Nichols GL (2000) Molecular epidemiological analysis of Cryptosporidium spp. in the United Kingdom: results of genotyping Cryptosporidium spp. in 1,705 fecal samples from humans and 105 fecal samples from livestock animals. J Clin Microbiol 38:3984-90

Medema GJ, Schijven JF (2001) Modelling the sewage discharge and dispersion of Cryptosporidium and Giardia in surface water. Water Res 35:4307-4316

Millard PS, Gensheimer KF, Addiss DG, Sosin DM, Beckett GA, Houck-Jankoski A, Hudson A (1994) An outbreak of cryptosporidiosis from fresh-pressed apple cider. J Am Med Assoc 272:1592-1596

Miron D, Kenes J, Dagan R (1991) Calves as a source of an outbreak of cryptosporidiosis among young children in an agricultural closed community. Pediatr Infect Dis J 10:438-441
Morgan UM, Xiao L, Fayer R, Lal AA, Thompson RC (2000) Epidemiology and strain variation of Cryptosporidium parvum. Contrib Microbiol 6:116-139

Ono K, Tsuji H, Rai SK, Yamamoto A, Masuda K, Endo T, Hotta H, Kawamura T, Uga S (2001) Contamination of river water by Cryptosporidium parvum oocysts in western Japan. Appl Environ Microbiol 67:3832-3836

Peng MM, Xiao L, Freeman AR, Arrowood MJ, Escalante AA, Weltman AC, Ong CS, MacKenzie WR, Lal AA, Beard CB (1997) Genetic polymorphism among Cryptosporidium parvum isolates: evidence of two distinct human transmission cycles. Emerg Infect Dis 3:567-573

Peng MM, Matos O, Gatei W, Das P, Stantic-Pavlinic M, Bern C, Sulaiman IM, Glaberman S, Lal AA, Xiao L (2001) A comparison of Cryptosporidium subgenotypes from several geographic regions. J Eukaryot Microbiol [Suppl]:28S-31S

Rose JB (1997) Environmental ecology of Cryptosporidium and public health implications. Annu Rev Public Health 18:135-161

Rouquet V, Homer F, Brignon JM, Bonne P, Cavard J (2000) Source and occurrence of Giardia and Cryptosporidium in Paris rivers. Water Sci Technol 41:79-86

Sischo WM, Atwill ER, Lanyon LE, George J (2000) Cryptosporidia on dairy farms and the role these farms may have in contaminating surface water supplies in the northeastern United States. Prev Vet Med 43:253-267

Strong WB, Gut J, Nelson RG (2000) Cloning and sequence analysis of a highly polymorphic Cryptosporidium parvum gene encoding a 60-kilodalton glycoprotein and characterization of its 15 - and 45-kilodalton zoite surface antigen products. Infect Immun 68:4117-4134

Sulaiman IM, Lal AA, Xiao L (2001) A population genetic study of the Cryptosporidium parvum human genotype parasites. J Eukaryot Microbiol [Suppl]:24S-27S

Ward PI, Deplazes P, Regli W, Rinder H, Mathis A (2002) Detection of eight Cryptosporidium genotypes in surface and waste waters in Europe. Parasitology 124:359-368

Xiao L, Morgan UM, Limor J, Escalante A, Arrowood M, Shulaw W, Thompson RCA, Fayer R, Lal AA (1999) Genetic diversity within Cryptosporidium parvum and related Cryptosporidium species. Appl Environ Microbiol 65:3386-3391

Xiao L, Morgan UM, Fayer R, Thompson RC, Lal AA (2000) Cryptosporidium systematics and implications for public health. Parasitol Today 16:287-292

Xiao L, Bern C, Limor J, Sulaiman I, Roberts J, Checkley W, Cabrera L, Gilman RH, Lal AA (2001a) Identification of 5 types of Cryptosporidium parasites in children in Lima, Peru. J Infect Dis 183:492-497

Xiao L, Singh A, Limor J, Graczyk TK, Gradus S, Lal A (2001b) Molecular characterization of Cryptosporidium oocysts in samples of raw surface water and wastewater. Appl Environ Microbiol 67:1097-1101 